\title{
Retenção de poluentes em filtros orgânicos operando com águas residuárias da suinocultura ${ }^{1}$
}

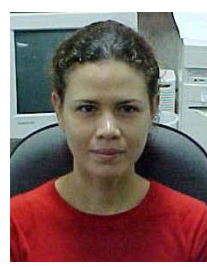

\author{
Viviane dos S. Brandão², Antônio T. de Matos ${ }^{3}$, Maurício P. F. Fontes ${ }^{4}$ \& Mauro A. Martinez ${ }^{5}$
}

\begin{abstract}
${ }^{1}$ Parte da Dissertação do primeiro autor para obtenção do título de Mestre em Engenharia Agrícola,
2 Doutorando no DEA/UFV. Av. P.H. Rolfs s/n, CEP 36571-000, Viçosa, MG. E-mail: vbrandao@buynet.com.br (Foto)

3 DEA/UFV. Fone: (31) 3899-1886, Fax: (31) 3899-2635. E-mail: atmatos@mail.ufv.br

4 DS/UFV. Fone: (31) 3899-1057,Fax: (31) 3899-2648. E-mail: mpfontes@mail.ufv.br

5 DEA/UFV. Fone: (31) 3899-1910, Fax: (31) 3899-2635. E-mail: mmauro@mail.ufv.br
\end{abstract}

Protocolo 33 - 26/3/2002 - Aprovado em 22/7/2003

\begin{abstract}
Resumo: Para aproveitamento das águas residuárias da suinocultura na fertirrigação de culturas agrícolas, principalmente no caso do uso de irrigação localizada, torna-se necessária a remoção dos sólidos em suspensão e de parte dos dissolvidos. Como, para esse tipo de água o uso de filtros convencionais de areia não é possível, torna-se necessário o estudo de materiais alternativos para uso como filtros. Como materiais filtrantes foram avaliadas a casca de arroz, a casca de frutos do cafeeiro, o bagaço de cana-de-açúcar, o sabugo de milho triturado, a serragem de madeira e o fino de carvão vegetal. As colunas de filtragem foram constituídas de tubos de PVC de $100 \mathrm{~mm}$ de diâmetro e comprimento de $600 \mathrm{~mm}$, sendo preenchidas com o material até a altura de $500 \mathrm{~mm}$ e com compressão de $12.490 \mathrm{~N} \mathrm{~m}^{-2}$. Avaliaram-se as alterações químicas e físicas ocorridas no material após seu uso como filtro no tratamento de $15 \mathrm{~L}$ de águas residuárias da suinocultura. Os materiais filtrantes que apresentaram maior capacidade de retenção de poluentes foram o bagaço de cana-de-açúcar e a serragem de madeira.
\end{abstract}

Palavras-chave: águas residuárias da suinocultura, filtros orgânicos, tratamento de resíduos

\section{Retention of pollutants in organic filters operating with swine confinement wastewater}

\begin{abstract}
For the utilization of wastewater from swine confinement in fertigation of agricultural crops, mainly in the case of localized irrigation, it is necessary to remove the suspended solids and some of the dissolved ones. Since the use of conventional sand filters for wastewater is not possible there is a need for a study concerning alternative materials that might be used as wastewater filters. The following filtering materials were evaluated: rice husk, coffee husk, sugarcane bagasse, milled corncob, sawdust and fine charcoal. The filtration columns consisting of PVC tubes with $100 \mathrm{~mm}$ diameter and $600 \mathrm{~mm}$ length were filled with filtering material up to $500 \mathrm{~mm}$ height and compression of $12,490 \mathrm{~N} \mathrm{~m}^{-2}$. Evaluations were performed for the chemical and physical changes occurring in the material following its use as a filter in treatment with swine wastewater. The filtering materials showing a higher retention capacity for the pollutants were the sugarcane bagasse and sawdust.
\end{abstract}

Key words: swine confinement wastewater, organic filters, residue treatments

\section{INTRODUÇÃO}

A suinocultura moderna é uma atividade pecuária concentradora de dejetos em pequenas áreas. A produção e o acúmulo de grande quantidade de resíduos nas granjas suinícolas fazem com que esta atividade tenha elevado potencial poluidor para o solo, o ar e a água. O potencial poluidor das águas residuárias da suinocultura está relacionado à presença de sólidos em suspensão e dissolvidos, matéria orgânica, nutrientes (nitrogênio e fósforo, dentre outros), patógenos, metais pesados e sais diversos.
Nos últimos 15 anos, tem-se dado maior atenção à necessidade de desenvolvimento tecnológico, com vistas à disposição dos resíduos gerados por animais, de forma a causar o mínimo impacto sobre o ambiente.

A legislação ambiental vigente determina que, no caso de lançamento de efluente em cursos d'água, a $\mathrm{DBO}_{5}$ a $20^{\circ} \mathrm{C}$ deve ser no máximo de $60 \mathrm{mg} \mathrm{L}^{-1}$, cujo limite somente poderá ser atingido, ou mesmo ultrapassado, caso a eficiência do sistema de tratamento seja maior que $85 \%$ em termos de redução de $\mathrm{DBO}$ e, ainda, quando o efluente lançado não altere os padrões de qualidade ou classificação em que o curso d'água esteja enquadrado (von Sperling et al., 1995). 
Por se tratar de técnica de disposição que barateia os custos de tratamento e por trazer benefícios agrícolas, o aproveitamento de águas residuárias da suinocultura na fertirrigação de culturas agrícolas tem despertado o interesse de agricultores, pressionados pelas exigências estabelecidas na legislação ambiental e a necessidade de baixar custos operacionais; entretanto, em razão da grande quantidade de material sólido suspenso e dissolvido presente nas águas residuárias da suinocultura e mesmo após ter passado por um tanque de sedimentação, muitos problemas de entupimento de bombas, tubulações e, principalmente, emissores, têm sido verificados.

A filtragem da água residuária da suinocultura, como etapa de tratamento do líquido antes de seu bombeamento, pode tornar menos problemática a aplicação e a distribuição dessas águas na cultura agrícola. A ação mecânica de eliminação dos sólidos em suspensão por filtração está baseada no princípio de que um meio poroso pode reter impurezas de dimensões menores que as dos poros da camada filtrante (Povinelli \& Martins, 1973). No entanto, esses mecanismos de remoção são temporários ou finitos, tendo em vista a obstrução gradativa dos poros do leito filtrante, com o conseqüente aumento da perda de carga no filtro.

Por ser a água residuária de granjas suinícolas muito rica em sólidos em suspensão e dissolvidos, o uso de filtros convencionais de areia não é recomendável, dado a sua rápida colmatação superficial e o impedimento ao fluxo normal da água residuária, razão por que se torna necessário o uso de materiais filtrantes alternativos. A utilização de materiais orgânicos, com capacidade para absorver/adsorver solutos, reter sólidos em suspensão e que sejam subprodutos de atividades agropecuárias e industriais, torna-se opção interessante, vistos a sua abundância, o seu baixo custo de aquisição e o fato de serem resíduos que podem ser dispostos de forma harmônica no ambiente.

Resíduos orgânicos, como a casca de arroz, a casca de frutos de cafeeiro, o bagaço de cana-de-açúcar, o sabugo de milho, a serragem de madeira e o fino de carvão vegetal, podem constituir importante opção de material filtrante para o uso no tratamento de águas residuárias de suinocultura. Após suplantada a capacidade filtrante desses materiais, a eficiência de tratamento deverá diminuir, o que tornará necessária a substituição do filtro em intervalos definidos de tempo. Os materiais filtrantes utilizados, ou seja, saturados de material absorvido, adsorvido ou simplesmente retido em seus poros, constituem lotes de material a ser compostado, podendo produzir, ao final do período de maturação, adubo orgânico de considerável valor fertilizante.

O presente trabalho teve como objetivo avaliar as alterações químicas nos materiais orgânicos utilizados como filtro de águas residuárias de suinocultura.

\section{MATERIAL E MÉTODOS}

Para determinação das alterações químicas e capacidade de retenção de poluentes pelos materiais filtrantes, realizou-se um experimento (conduzido nos dias 31/10 e 1/11/1998), utilizando-se seis tipos de resíduo orgânico e quatro repetições, esquematizado em delineamento inteiramente casualizado. $\mathrm{O}$ mesmo foi montado em casa-de-vegetação da Área Experimental de Hidráulica e Irrigação e Drenagem do Departamento de Engenharia Agrícola da UFV - Viçosa, MG.

O bagaço de cana-de-açúcar e o fino de carvão vegetal foram previamente triturados. Todos os materiais foram peneirados em malha de $2,0 \mathrm{~mm}$, sendo utilizado para a construção dos filtros o material retido nas peneiras. No caso da casca de arroz, foi utilizada uma malha de $0,5 \mathrm{~mm}$. O fino de carvão vegetal, devido a sua desuniformidade, teve suas dimensões enquadradas entre os limites de 2,0 a 6,0 mm. Todos os materiais foram secados ao ar, antes do acondicionamento nas colunas. As colunas de filtração foram constituídas por tubos de PVC de $100 \mathrm{~mm}$ de diâmetro e $600 \mathrm{~mm}$ de altura, em cuja na extremidade inferior foi colado um tampão com uma perfuração no centro, em que foi adaptada uma mangueira flexível de $10 \mathrm{~mm}$, para permitir a saída do efluente da coluna. Na parte interna do orifício utilizou-se uma tela de nylon de 0,5 $\mathrm{mm}$ de malha para evitar a saída do próprio material filtrante e, na parte superior da coluna, utilizou-se outra tela de nylon de $0,5 \mathrm{~mm}$ de malha, para que o material filtrante não flutuasse ao entrar em contato com a água residuária.

Para evitar a formação de fluxo preferencial dentro das colunas de filtração, o próprio material filtrante foi colado nas paredes internas dos tubos, formando uma fina camada para que, então, fosse iniciado o preenchimento das colunas. Com o mesmo objetivo comprimiu-se, com a ponta dos dedos, a periferia de cada camada a medida em que elas foram acrescentadas. O preenchimento foi feito em camadas de $5,0 \mathrm{~cm}$, submetidas uma a uma a compressão de $12490 \mathrm{~N} \mathrm{~m}^{-2}$, até que se alcançasse a altura de $50 \mathrm{~cm}$.

A água residuária foi coletada em uma propriedade suinícola de criação de 250 matrizes, localizada em São Miguel do Anta, MG, em um tanque de estocagem receptor da água proveniente de todas as baias. A água residuária foi passada em peneira de malha de 5,0 mm, simulando-se um pré-tratamento.

Recipientes de $60 \mathrm{~L}$ foram utilizados para estocagem da água residuária durante o experimento, e perfurados na sua base, para a adaptação de uma mangueira de $25,4 \mathrm{~mm}$ de diâmetro, à qual foi adaptada uma torneira para controle do fluxo de entrada nas colunas (Figura 1). Mantendo-se fechada a saída da coluna de filtração, as seis colunas foram saturadas simultaneamente com a água residuária até a altura de $50 \mathrm{~cm}$, para então se acionar o cronômetro quando, a partir daí, se permitiu a saída do efluente. $\mathrm{O}$ experimento foi finalizado quando o total de $15 \mathrm{~L}$ de efluentes havia sido coletado de cada coluna. Ao final do período de filtração, amostras do terço superior, mediano e inferior do material filtrante, foram coletadas para análise química.

A partir do conhecimento do volume ocupado e da massa do material, foi possível calcular-se a massa específica global do material filtrante, em que a massa específica das partículas de cada material foi determinada seguindo-se a metodologia da EMBRAPA (1997). De posse desses valores (massa específica global e das partículas) foi possível, então, se calcular a porosidade do material filtrante e o volume de poros (volume ocupado pelos poros da coluna de material filtrante).

Para caracterização da água residuária afluente, foram coletadas, aleatoriamente, quatro amostras de 1,5 L nos 


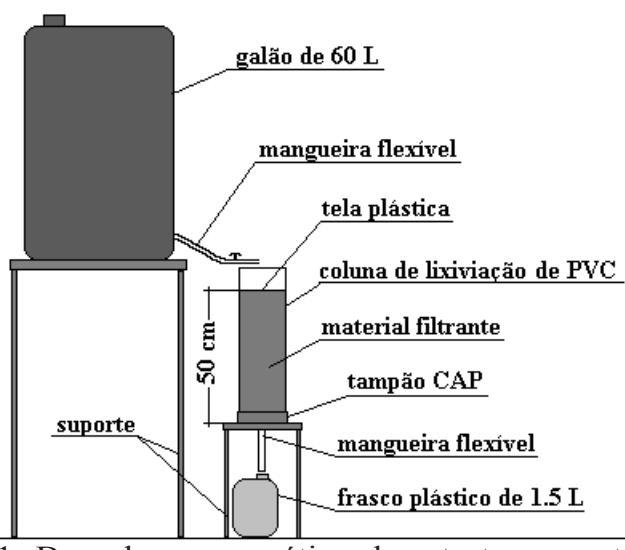

Figura 1. Desenho esquemático da estrutura montada para execução da filtragem da água residuária de suinocultura e da coleta do efluente dos filtros

recipientes de 60 L. Das amostras do afluente retiraram-se alíquotas de $200 \mathrm{~mL}$, que foram imediatamente acondicionadas em "freezer" $\left(-4^{\circ} \mathrm{C}\right)$ para posterior análise química. No restante das amostras do afluente determinaram-se: condutividade elétrica (CE), usando-se condutivímetro digital marca Orion, modelo 125; densidade, através do densímetro de escala: 1,000 a 1,100 (Scherer et al., 1995) e sólidos totais (ST) e sedimentáveis (SP) (Braile \& Cavalcanti, 1979). Os valores encontrados para esses parâmetros foram $6,234 \mathrm{dS} \mathrm{m}^{-1}, 1,005,88,250 \mathrm{~mL} \mathrm{~L}^{-1} \mathrm{e}$ $5,500 \mathrm{~g} \mathrm{~L}^{-1}$, respectivamente.

$\mathrm{O}$ teor de $\mathrm{N}$-total da água residuária afluente foi determinado em alíquota de 3,0 mL, pelo método de Kjeldahl (Tedesco et al., 1985), sendo que a água residuária da suinocultura apresentou concentração de 0,0936 dag L L ${ }^{-1}$ de N-total, enquanto alíquotas de 5,0 $\mathrm{mL}$ foram mineralizadas via digestão nítrico-perclórico (3 $\mathrm{mL}$ de ácido nítrico: $1 \mathrm{~mL}$ de ácido perclórico). Nos extratos de digestão, as concentrações de $\mathrm{Ca}^{2+}, \mathrm{Mg}^{2+}, \mathrm{Cu}^{2+} \mathrm{e} \mathrm{Zn}^{2+}$ foram determinadas por espectrofotometria de absorção atômica, sendo as concentrações de $\mathrm{K}^{+}$e $\mathrm{Na}^{+}$determinadas por fotometria de emissão de chama e as do P-total, por colorimetria, pelo método do ácido ascórbico, modificado por Braga \& Defelipo (1974).

Nos resíduos orgânicos a serem utilizados como filtro, realizaram-se as seguintes análises físicas: determinação do conteúdo de umidade (Kiehl, 1985) e da massa específica de partículas do material filtrante; as análises químicas dos resíduos constituíram-se na determinação do $\mathrm{pH}\left(\mathrm{H}_{2} \mathrm{O}\right.$ e $\left.\mathrm{KCl}\right)$ e soma de bases removíveis (valor $\mathrm{S}$ ). $\mathrm{O} \mathrm{pH}$ foi determinado pelo método potenciométrico, utilizando-se os extratores de $\mathrm{KCl} 1$ mol L ${ }^{-1}$, para determinação de $\mathrm{Ca}^{2+} \mathrm{e} \mathrm{Mg}^{2+} ; \mathrm{HCl} 0,05 \mathrm{~mol} \mathrm{~L}^{-1}$, para determinação de $\mathrm{Na}^{+} \mathrm{e} \mathrm{K}^{+}$e acetato de cálcio, a $\mathrm{pH}$ 7, para determinação de $\mathrm{H}^{+} \mathrm{e} \mathrm{Al}^{3+}$ (EMBRAPA, 1997).

Na Tabela 1 apresentam-se os valores de umidade (U), as massas específicas das partículas $\left(\rho_{\mathrm{p}}\right)$ e global $\left(\rho_{\mathrm{g}}\right)$, porosidade (P) e volume ocupado pelos poros $\left(\mathrm{V}_{\mathrm{t}} \mathrm{P}\right), \mathrm{pH}, \Delta \mathrm{pH}$, acidez e valor $\mathrm{S}$, para cada material filtrante avaliado.

Dos resíduos orgânicos "in natura" e daqueles coletados após uso nas colunas de filtração (previamente descongelados e secos a $60-65^{\circ} \mathrm{C}$, por $48 \mathrm{~h}$, em estufa de circulação forçada e moídos em moinho de folha Haley), retiraram-se amostras de 0,5 g para determinação do N-total, pelo método Kjeldahl, e para mineralização, via digestão nítrico-perclórico $(3 \mathrm{~mL}$ de ácido nítrico: $1 \mathrm{~mL}$ de ácido perclórico). No extrato, foram feitas as mesmas determinações já citadas para o afluente. Nesses mesmos materiais, foi determinado o conteúdo de C-orgânico, pelo método da perda por ignição (Kiehl, 1985).

As análises estatísticas compreenderam análises de variância e teste $\mathrm{F}$ para comparar possíveis efeitos do tratamento pelo estudo de contrastes de interesse. As análises estatísticas foram processadas utilizando-se o pacote estatístico SAS (1990).

\section{RESULTADOS E DISCUSSÃO}

A taxa de infiltração tendeu a valores entre $100 \mathrm{e} 150 \mathrm{~cm} \mathrm{~h}^{-1}$ $\left(24 \mathrm{e} 36 \mathrm{~m} \mathrm{~d}^{-1}\right)$ na maioria dos materiais filtrantes. Tais valores são intermediários entre aqueles recomendados para uso em filtros lentos (2 a $\left.9 \mathrm{~m} \mathrm{~d}^{-1}\right)$ (Povinelli \& Martins, 1973) e filtros rápidos (120 a $\left.240 \mathrm{~m} \mathrm{~d}^{-1}\right)$ (Steel \& McGhee, 1979).

Como os valores de $\mathrm{pH}\left(\mathrm{H}_{2} \mathrm{O}\right)$ estão superiores aos de $\mathrm{pH}$ ( $\mathrm{KCl}$ ), foram obtidos valores de $\Delta \mathrm{pH}$ negativo para todos os materiais filtrantes, significando que os materiais em questão são eletronegativos, ou seja, as cargas negativas predominam em relação às cargas positivas.

Dentre os resíduos orgânicos utilizados como material filtrante, o bagaço de cana-de-açúcar, a serragem de madeira e a casca de arroz foram os que se mostraram mais eletronegativos, enquanto a casca de frutos do cafeeiro, o sabugo de milho e o fino de carvão vegetal foram os de menor eletronegatividade. Acredita-se que, em parte, esses resultados possam ser atribuídos à maior superfície específica dos primeiros.

Tabela 1. Características físicas e químicas dos materiais filtrantes utilizados

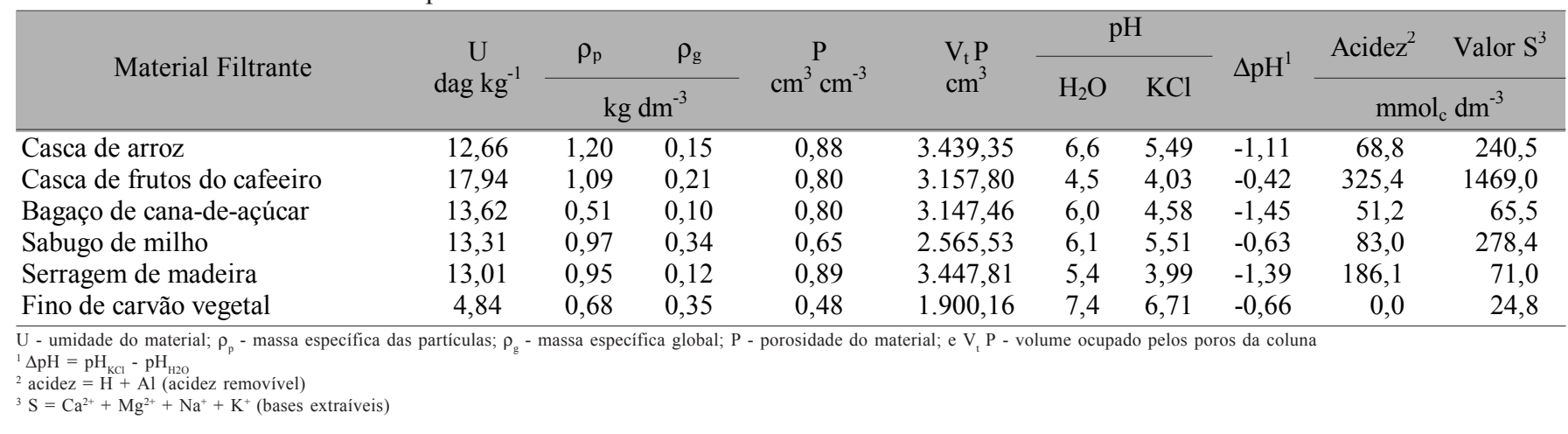


Os valores de soma de bases $(\mathrm{S})$ e acidez $(\mathrm{H}+\mathrm{Al})$ indicam ser o material filtrante detentor de cátions extraíveis com ácidos fracos, podendo estar adsorvidos no complexo de troca ou não. A soma dos cátions adsorvidos ao complexo de troca seria indicação do valor de CTC do material. Neste aspecto e quanto maiores os valores de CTC, maior será a capacidade do material filtrante em reter os cátions presentes nas águas residuárias de suinocultura.

Os valores das análises químicas da água residuária afluente e efluente dos filtros orgânicos são apresentados na Tabela 2. Pequena ou nenhuma alteração foi detectada na concentração de N-total, $\mathrm{Ca}, \mathrm{Mg}$ e $\mathrm{Zn}$ no efluente do filtro, enquanto a concentração de P-total, Na e K aumentou no efluente obtido em filtros de casca de arroz, casca de café e sabugo de milho. Significativa redução na concentração de $\mathrm{Cu}$ foi constatada para todos os materiais utilizados como filtro, atingindo-se eficiência de remoção de até $43,6 \%$.

$\mathrm{Na}$ Tabela 3 tem-se a caracterização química do material filtrante no perfil da coluna, antes e após a filtragem de $15 \mathrm{~L}$ de água residuária da suinocultura. $\mathrm{O}$ contraste $\mathrm{C} 1$ compara $\mathrm{o}$ material original, ou seja, antes da filtragem, com as diferentes partes ao longo do perfil da coluna; o contraste $\mathrm{C} 2$ compara a parte superior da coluna com as demais partes; já o contraste $\mathrm{C} 3$ defronta a parte mediana com a parte inferior.

Com relação à concentração de fósforo (P-total) os contrastes estudados para os materiais filtrantes casca de arroz, sabugo de milho e fino de carvão vegetal não apresentaram diferenças significativas, pelo teste $\mathrm{F}$, antes e após a filtragem ao longo do perfil da coluna, mas, o bagaço de cana-de-açúcar e a serragem de madeira sofreram enriquecimento desse elemento, sendo que estes apresentaram maior retenção na parte superior do perfil da coluna de lixiviação, o que é um indicativo da grande reatividade desse material. A casca de frutos de cafeeiro apresentou comportamento muito distinto dos outros resíduos orgânicos, ou seja, liberou fósforo para a água residuária. Em termos de tratamento da água residuária, isto é um fator negativo, já que o material filtrante prejudicou ainda mais a qualidade do efluente, no que se refere à concentração de $\mathrm{P}$ em solução.

Quanto ao nitrogênio (N-total) a maioria dos materiais filtrantes teve acréscimo deste elemento após a filtragem, com exceção da casca de fruto de cafeeiro e do sabugo de milho. Para o caso da serragem de madeira houve maior retenção na parte superior da coluna, ratificando a maior reatividade deste material. $\mathrm{O}$ aumento da concentração de nitrogênio no material filtrante seria muito desejável, considerando-se que a redução da relação $\mathrm{C} / \mathrm{N}$ é fundamental para posterior compostagem do material orgânico.

A concentração de C-orgânico no material filtrante não variou com a filtragem ao longo da coluna, à exceção da casca de frutos de cafeeiro e do sabugo de milho, que sofreram incremento da concentração deste elemento, porém a relação $\mathrm{C} / \mathrm{N}$ decresceu na maioria dos materiais filtrantes, resultado do aumento da concentração de $\mathrm{N}$ nos resíduos orgânicos. Exceções ocorreram no sabugo de milho e na casca de fruto de cafeeiro, uma vez que houve incremento da concentração de C-orgânico com a filtragem, sem que houvesse aumento significativo da concentração de $\mathrm{N}$.

Com relação ao cálcio, os materiais orgânicos casca de arroz, casca de frutos do cafeeiro, bagaço de cana-de-açúcar e serragem de madeira retiveram significativamente a presença desse elemento. Na casca de fruto de cafeeiro e na serragem de madeira, a retenção foi mais acentuada na parte superior do perfil da coluna que nas demais partes; já o sabugo de milho e o fino de carvão vegetal não apresentaram diferenças significativas na concentração de $\mathrm{Ca}$, após seu uso na filtragem da água residuária da suinocultura.

No que se refere ao magnésio, não houve retenção significativa deste elemento após a filtragem, quando os materiais filtrantes foram a casca de frutos de cafeeiro, o bagaço de cana-de-açúcar, o sabugo de milho e o fino de carvão vegetal. Por outro lado, a casca de arroz sofreu redução da concentração de $\mathrm{Mg}$, liberando-o para a água residuária. Somente a serragem de madeira foi capaz de reter significativamente o magnésio após a filtragem, sendo esta retenção mais acentuada na parte superior da coluna.

Tanto o sódio como o potássio, elementos que se encontram quase que totalmente na forma mineral na água residuária (Scherer et al., 1995) tiveram suas concentrações reduzidas na casca de arroz, na casca de frutos do cafeeiro e no sabugo de milho. O bagaço de cana-de-açúcar reteve $\mathrm{Na}$; entretanto, não ocorreu diferença significativa na concentração de K no material filtrante, após seu uso como filtro de água residuária da suinocultura. Retenções de sódio e de potássio foram observadas na serragem de madeira, que teve suas concentrações aumentadas após seu uso como filtro. As concentrações de ambos os elementos no fino de carvão vegetal não foram alteradas após a filtragem. As elevadas disponibilidades de sódio e potássio contidas nos materiais orgânicos podem estar associadas às altas solubilidades de sais presentes ou deslocados do complexo de troca.

Tabela 2. Caracterização química da água residuária de suinocultura (ARS) afluente (AF) e efluente (EF) dos filtros orgânicos após a filtragem de $15 \mathrm{~L}$

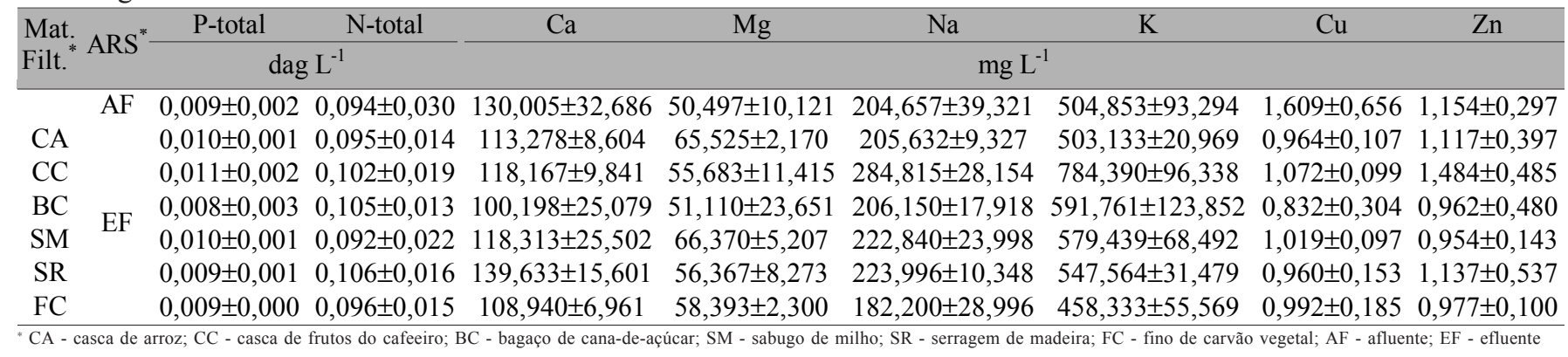


Tabela 3. Valores médios da análise química do material filtrante antes e após a filtragem da água residuária da suinocultura e valores do teste F para estudo de contrastes

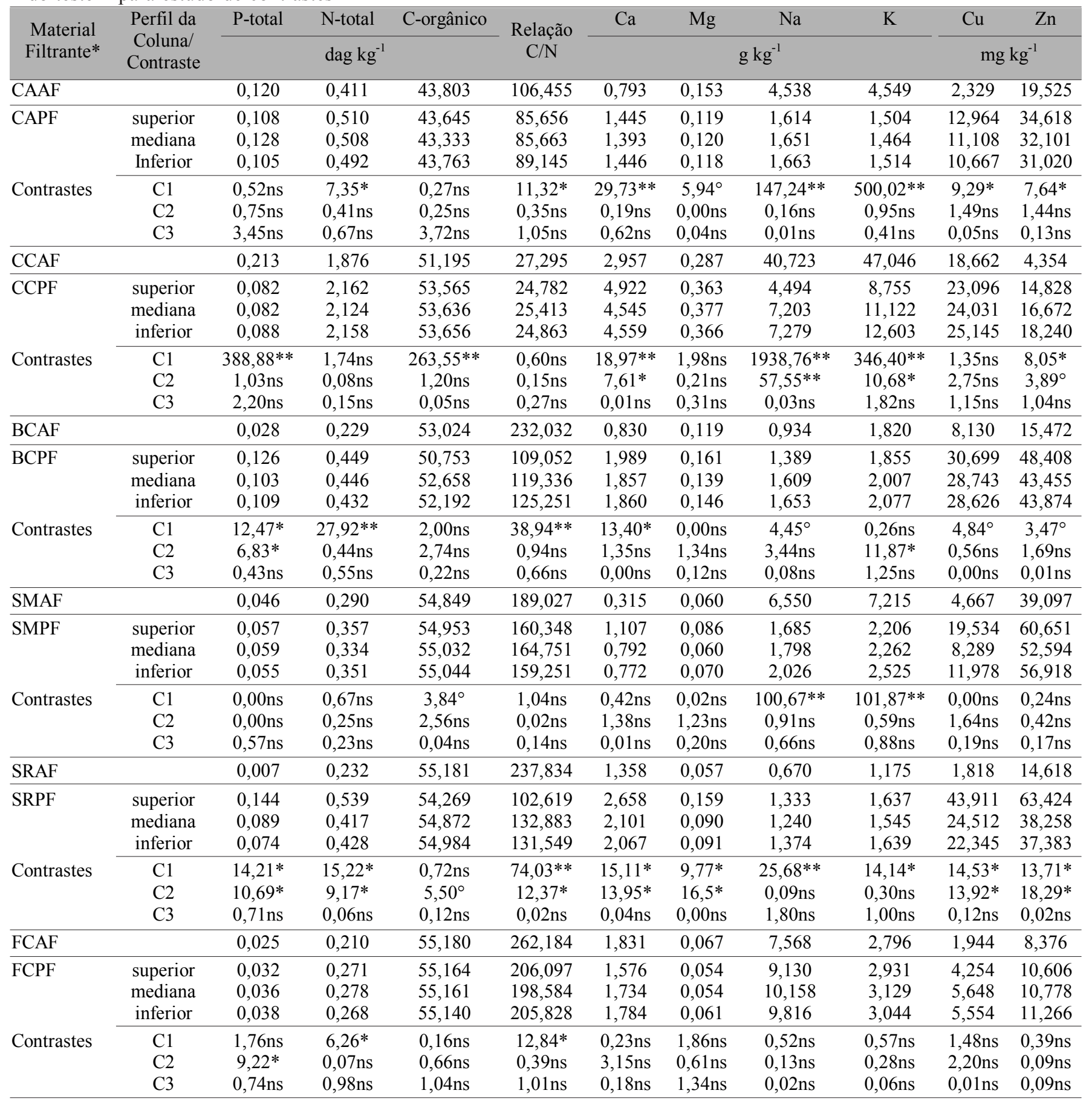

* CAAF - casca de arroz antes da filtragem; CAPF - casca de arroz após a filtragem; CCAF - casca de frutos do cafeeiro antes da filtragem; CCPF - casca de frutos do cafeeiro após filtragem; BCAF - bagaço de cana-de-açúcar antes da filtragem; BCPF - bagaço de cana-de-açúcar após a filtragem; SMAF - sabugo de milho antes da filtragem; SMPF - sabugo de milho após a filtragem; SRAF - serragem de madeira antes da filtragem; SRPF - serragem de madeira após a filtragem; FCAF - fino de carvão vegetal antes da filtragem; FCPF - fino de carvão vegetal após a filtragem

$\mathrm{C} 1=3 *$ original $-($ superior + mediana + inferior $) ; \mathrm{C} 2=2 *$ superior $-($ mediana + inferior $) ; \mathrm{C} 3=$ mediana - inferior

**, $*{ }^{\circ}$ e ns indicam, respectivamente, significância em nível de $1 \%, 5 \%, 10 \%$ e não significativo

Com relação a $\mathrm{Cu}$, verificou-se aumento da concentração deste elemento dos materiais filtrantes, casca de arroz, bagaço de cana-de-açúcar e serragem de madeira, sendo que esta última novamente apresentou maior retenção na parte superior da coluna. A casca de fruto de cafeeiro, o sabugo de milho e o fino de carvão vegetal não tiveram a concentração de $\mathrm{Cu}$ alterada após a filtragem; o mesmo comportamento foi constatado para o Zn; entretanto, a retenção de Zn ocorreu principalmente na parte superior da coluna. A retenção de metais pesados em resíduos orgânicos (casca de arroz) foi verificada por Munaf \& Zein (1997). Esses autores obtiveram retenção de até $85 \%$ dos metais pesados $\mathrm{Cr}^{2+}, \mathrm{Zn}^{2+}, \mathrm{Cu}^{2+} \mathrm{e} \mathrm{Cd}^{2+}$ em solução, dependendo do tamanho das partículas de casca de arroz.

Acredita-se que, com a redução do tamanho das partículas do material orgânico utilizado nos filtros, maiores eficiências de remoção de metais pesados e outros poluentes sejam alcançadas devido à maior possibilidade de retenção de sólidos 
nos pequenos poros, ao aumento da superfície específica e à exposição de maior número de sítios de troca do material filtrante.

\section{CONCLUSÕES}

1. Dentre os materiais orgânicos avaliados, o bagaço de cana-de-açúcar e a serragem de madeira foram os mais promissores para a utilização como material filtrante, porque apresentaram maior capacidade de reter elementos químicos;

2. Os aumentos da concentração de $\mathrm{Cu}$ no bagaço de canade-açúcar e serragem de madeira foram de 3,8 e 24,1 vezes, respectivamente, após a filtragem da água residuária da suinocultura, enquanto que a concentração de $\mathrm{Zn}$ teve aumentos de 3,1 e 4,3 vezes nestes mesmos materiais;

3. O aumento da concentração de $\mathrm{N}$-total no material filtrante após o tratamento da água residuária da suinocultura fez com que a relação $\mathrm{C} / \mathrm{N}$ reduzisse, o que é fundamental para posterior compostagem do mesmo;

4. É possível que a remoção dos elementos químicos aqui mencionados esteja associada à própria retenção física dos sólidos dissolvidos ou em suspensão na água residuária da suinocultura.

\section{LITERATURA CITADA}

Braga, J.M.; Defelipo, B.V. Determinação espectrofotométrica de fósforo em extratos de solo e material vegetal. Revista Ceres, Viçosa, v.21, p.73-85, 1974.
Braile, P.M.; Cavalcanti, J.E.W.A. Manual de tratamento de águas residuárias industriais. São Paulo: CETESB, 1979. 764p.

EMBRAPA - Empresa Brasileira de Pesquisa Agropecuária Manual de método de análises de solo. 2. ed. Rio de Janeiro, 1997.212p.

Kiehl, E.L. Fertilizantes orgânicos. Piracicaba: Ed. Agronômica Ceres, 1985.492p.

Munaf, E., Zein, R. The use of rice husk for removal of toxic metals from waste water. Environmental Technology, v.18, p.359-362, 1997.

Povinelli, J.; Martins, F. Pesquisa sobre a eficiência de filtros lentos em unidades piloto. In: Congresso Brasileiro de Engenharia Sanitária, 7, São Carlos, 1973, Separata. São Carlos: EESC - USP, 1973.20p.

SAS - Statistic analysis system. Users's guide version 6. 4. ed., volume 1. Carry: SAS Institute Inc., 1990. 890p.

Scherer, E.E.; Baldissera, I.T.; Dias, L.F.X. Método rápido para determinação da qualidade fertilizante do esterco líquido de suíno a campo. Agropecuária Catarinense, Florianópolis, v.8, p.40-43, 1995 .

Steel, E.W.; McGhee, T.J. Water supply and sewerage. 5. ed. New York: McGraw-Hill Book Company, 1979. 665p.

Tedesco, J.M.; Volkweiss, S.J.; Bohnen, H. Análises de solo, plantas e outros materiais. Porto Alegre: UFRGS, 1985. 186p. Boletim Técnico de Solos, 5

von Sperling, M.; Costa, A.M.L.M.; Castro, A.A. Esgotos sanitários. In: Barros, R.T.V., Chernicharo, C.A.L., Heller, L., von Sperling, M. (ed.). Manual de saneamento e proteção ambiental para os municípios. Belo Horizonte: DESAIUFMG, 1995. v.2, p.113-160. 